\title{
CONSCIÊNCIA HISTÓRICA, HISTÓRIA E CULTURA AFRO-BRASILEIRA NUM DIÁLOGO INTERTEXTUAL
}

\author{
HISTORICAL AWARENESS, HISTORY AND AFRO-BRAZILIAN CULTURE IN AN \\ INTERTEXTUAL DIALOGUE
}

\begin{abstract}
Dueli do Nascimento
Mestre pelo Programa de Pós-Graduação em Educação pela Universidade Estadual de Mato Grosso do Sul - Paranaíba/MS, graduada em Pedagogia, Letras e História, Professora no Centro Universitário Católico Salesiano Auxilium. Araçatuba, SP - Brasil. sueli.unisalesiano@gmail.com

Diogo da Silva Roiz
Dós-doutorado e doutor em História pela Universidade Federal do Paraná (UFPR), Professor na
Universidade Estadual de Mato Grosso do Sul.
Paranaíba, MS - Brasil.
diogosr@uems.br
\end{abstract}

Resumo: A pesquisa foi desenvolvida na linha de pesquisa História, Sociedade e Educação sobre o ensino da História e da Cultura Afro-Brasileira, com o objetivo de fomentar mudanças na consciência histórica, pela via transitiva ingênua freireana, e pela via prévia rüseniana, a partir do saber histórico dos/as acadêmicos/as dos cursos superiores em Engenharia da Computação, Tecnologia em Desenvolvimento de Sistemas, Tecnologia em Desenvolvimento de Jogos Digitais e Engenharia Civil, em 2018 e 2019. Os conteúdos integraram a elaboração e a representação narrativa da continuidade temporal - passado, presente e futuro -, com base: numa pesquisa-ação e num tratamento qualitativo dos dados, intermediados por linguagens culturais (obras literárias, filmes e documentários brasileiros) do século XVIII ao XXI, escolhidos entre os nomes mais representativos de cada área. A conclusão é que o processo de formação da consciência histórica foi atingido, tanto em relação à desconstrução das ideias maniqueístas e à linearidade histórica, quanto aos discursos racistas e egocentrados.

Palavras-chave: Consciência histórica. História e cultura afro-brasileira. Educação reflexiva.

Abstract: The research was developed in the line of research History, Society and Education on the teaching of AfroBrazilian History and Culture, with the objective of fostering changes in historical consciousness, through the naive Freirean transitive route, and through the Rüsenian previous route, starting from the historical knowledge of academics from higher education courses in Computer Engineering, Technology in Systems Development, Technology in Digital Game Development and Civil Engineering, in 2018 and 2019.The contents integrated the elaboration and narrative representation of temporal continuity - past, present and future - based on: - an action research and - a qualitative treatment of the data, - intermediated by cultural languages (Brazilian literary works, films and documentaries) from the 18th to the 21 st century, chosen from among the most representative names in each area. The conclusion is that the process of forming historical consciousness has been reached, both in relation to the deconstruction of manichaean ideas and historical linearity, as well as to racist and self-centered discourses.

Keywords: Historical consciousness. Afro-brazilian history and culture. Reflective education.

\section{Para citar - ABNT NBR 6023:2018}

NASCIMENTO, Sueli do; ROIZ, Diogo da Silva. Consciência histórica, história e cultura afro-brasileira num diálogo intertextual. Cadernos de Pós-graduação, São Paulo, v. 19, n. 2, p. 112-125, jul./dez. 2020. Disponível em: https://doi.org/10.5585/cpg.v19n2.16130. 
Introdução

[...] O passado direciona o presente e, com isso, estabelece o futuro. (ROIZ, 2017, p. 32)

A peculiar relação entre passado, presente e futuro, estabelecida num processo cotidiano de construção do pensamento histórico e da consciência, constitui o elo da proposta, que partiu de indagações submetidas aos/às alunos/as do Centro Universitário Católico Salesiano Auxilium (UniSALESIANO), dos cursos de tecnologia, na disciplina História e Cultura Afro-Brasileira e Indígena, e nas de Engenharia Civil, Ciências Humanas e Sociais. A faculdade tem cerca de 4.500 alunos e os mencionados cursos de tecnologia são: Tecnologia em Desenvolvimento de Sistemas, Tecnologia em Desenvolvimento de Jogos Digitais e Engenharia da Computação.

Cada registro cotidiano que vier a ser mencionado representa o ininterrupto fôlego para continuar a saga de uma nação na qual vejo você, vejo a mim e vejo a nós. Filhos e filhas na multiplicidade humana e mestiça, nesse processo cultural de "constituição de uma língua, o português brasileiro, na coexistência, ora ingrata, ora pacífica, de costumes, crenças, valores e expressões poéticas e lúdicas" de nossa transmutável essência, de seres freireanamente inconclusos.

Neste artigo, apresentaremos três etapas - questionário inicial, literatura, reaplicação do questionário inicial; em virtude, porém, da dinâmica original e extensa dos dados, expressaremos apenas uma parte da pesquisa desenvolvida, tão importante quanto as demais. Nela, destacam-se a construção e a desconstrução de conceitos registrados em sala de aula, focando aqui a temática afrobrasileira, mas cabe ressaltar que a dissertação, aprovada em defesa, retrata também a história e a cultura indígena.

A pesquisa-ação se centrou num tratamento qualitativo dos dados, objetivando: a) orientar a análise das narrativas; b) investigar a atribuição dos significados sobre negros e indígenas; c) averiguar eventual transformação conceitual ao longo do desenvolvimento da pesquisa e, assim, fomentar mudanças na consciência histórica.

Para a finalidade da transformação conceitual, temo-nos valido de Freire, particularmente de seu método de transição de uma consciência ingênua para uma consciência crítica; de Rüsen, para trabalhar o saber histórico dos/as acadêmicos/as.

Como meios, utilizamos livros literários, filmes e documentários brasileiros, enquanto linguagens da cultura do século XVIII ao século XXI, por tratarem, cada um em sua particular linguagem, os temas relativos ao ensino da história e da cultura afro-brasileira e indígena. Livros e autores foram escolhidos entre os mais notáveis relativamente ao lapso de tempo escolhido, e ao tema. 
Observamos, durante todo esse processo, que o ensino de História necessita de reflexão para um seu mais aprofundado conhecimento, como também da maior relevância à estratégia mencionada, enquanto ferramenta de análise da sociedade e, consequentemente, da formação da consciência histórica. Seguimos a percepção de Hall a respeito do que ocorria no final do século XX sobre o abalo de nós próprios como sujeitos integrados, quando afirma que "um tipo diferente de mudança estrutural está transformando as sociedades modernas", fragmentando, consequentemente, "as paisagens culturais de classe, gênero, sexualidade, etnia, raça e nacionalidade" (2015, p. 10).

Rüsen, por seu lado, nos tem levado a repensar a identidade, uma vez que as interpretações históricas "necessitam ser compatíveis com a particularidade da situação respectiva da vida e com a diferença constitutiva da identidade, da alteridade dos outros” (2015, p. 69).

Tal embasamento teórico tem sido fundamental para as indagações/argumentações propostas aos participantes, significativamente afetados pelo que Hall (2015) chama de descontinuidades, e que Paulo Freire (1987, p. 114) apresenta como "processo de conscientização". Isso era preciso para que esse mesmo homem inconcluso se transformasse em "sujeito, por uma reflexão sobre sua situação, sobre seu ambiente concreto".

\section{Metodologia: historicidade na leitura, interpretação e linguagem cultural}

Este processo metodológico foi desenvolvido durante um semestre para cada turma citada e predeterminada, respectivamente turmas A e B, dos cursos de tecnologia mencionados anteriormente na introdução, em 2018, e C - Engenharia Civil -, em 2019.

Nosso trajeto - da pesquisadora e acadêmicos/as - ocorreu por etapas didáticas: $1^{\circ}$ predeterminaram-se duas questões para delinear a (des)construção em sala de aula; $2^{\circ}$ apresentaram-se trechos de obras literárias predeterminadas, e filmes; $3^{\circ}$ - introduziram-se rupturas em suas narrativas (paralelo ao $2^{\circ}$ e contínuo), questionamentos (debates), resultando em dissertações e, enfim desafiando-os/as; $4^{\circ}$ - retomou-se o questionamento inicial, comparando as leituras previamente realizadas dos diálogos entre as diferentes linguagens culturais.

Quanto às etapas, predeterminaram-se duas questões específicas - utilizadas no início da pesquisa ( $1^{\mathrm{a}}$ etapa) e reaplicadas ao seu final, a serem respondidas por cada acadêmico/a: a) "como observa a participação dos indígenas/negros"; b) qual, para você, o significado das palavras “índio/negro na história do Brasil”.

A partir das questões, investigaram-se o ponto de vista dos/as acadêmicos/as, seus valores, preferências, preconceitos e comportamentos sobre a temática, provocando debates e discussões nos quais pudessem expressar o conhecimento histórico. Posteriormente, propôs-se o seguinte 
conteúdo: a) visão histórica e dialética dos processos sociais em curso: raça, racismo e o lugar do negro, conteúdo analisado na filmografia e na literatura.

No caso do filme: 1 - Vista Minha Pele, direção de Joel Zito Araújo. São Paulo: - Centro de Estudos das Relações de Trabalho e Desigualdades (Ceert), 2003, com duração de 24 minutos. A intenção era introduzir significados juntamente aos/às acadêmicos/as e, aos poucos, complementá-los com novos elementos, resultando nas em dissertações das turmas.

A estratégia quanto à literatura ocorreu num recorte histórico-literário do século XVIII aO XXI, feito de produções essencialmente brasileiras e de fácil acesso virtual, - julgadas pertinentes à temática da proposta. Para esse efeito foram escolhidas as seguintes obras: O Cortiço (1890), de Aluísio Azevedo; Pai Contra Mãe (1906), de Machado de Assis; Clara dos Anjos (1948), de Lima Barreto; Um Defeito de Cor (2006), de Ana Maria Gonçalves. Os primeiros, por tratarem diretamente do tema em seus tempos, quando os afro-brasileiros ainda não se expressavam através de obras escritas. O último, por se tratar de uma legítima representante negra. Quanto a Cidade de Deus: a história de Ailton, a escolha se deveu ao fato de representar, além de um caso frequente, as disparidades entre classes, ou, mais especificamente, entre uma suposta superioridade da raça branca sobre as outras. Não se trata propriamente de uma obra, mas do resultado de 60 horas de entrevistas, demonstrando a realidade vivida (História real), e não apenas o personagem cinematográfico criado pelo cinema.

Os livros foram enviados a cada estudante em PDF, embora também os tivessem disponíveis no formato físico - na coleção pessoal da professora. O objetivo desta atividade foi destacar trechos, personagens e o contexto em que cada um se inseria, para observar e discutir a representação e a participação do negro no desenrolar do enredo de cada livro.

A proposta de leitura foi destacar as personagens - fictícias ou não - em grupo, preferindo discutir coletivamente para cruzar opiniões. Em vez de respostas individuais, um escriba - alguém que para isso se oferecesse espontaneamente - anotaria as discussões de cada turma e, em seguida, redigiria o relato (dissertação) a ser exposto ao público das turmas, disso resultando um texto coletivo como síntese do debate de ideias.

A estratégia se pareceu a mais oportuna pela perspectiva de que assim a turma se sentiria mais à vontade para se manifestar sobre a temática; igualmente, uns e outros poderiam indagar e argumentar, expondo a construção e desconstrução conceitual, estudando e avaliando as diversas opiniões, aspecto fundamental na pesquisa-ação.

Para finalizar, aplicaram-se novamente as duas questões - ao final do ano letivo de 2018 e ao final do primeiro semestre de 2019: a) “Como observa a participação dos indígenas/negros”; b) Qual, para você, o significado das palavras "índio/negro na história do Brasil". 
O que foi exposto pelos/as acadêmicos/as será aqui desdobrado em dois aspectos: o da participação dos negros na história do país e na literatura, e o da passagem da consciência ingênua para a crítica (via Paulo Freire) e de uma visão da História também crítica, com o apoio da pedagogia de Rusen, nos itens 1.1 e 1.2 .

\subsection{Questionário: participação dos negros e significado da palavra na história do brasil sob a visão dos discentes}

Num processo de intervenção intencional entre sujeitos e professora, cabe a sensibilidade de notar tais movimentos, ora cristalizados e/ou enraizados, ora mensuráveis pelos agressivos resquícios coloniais que hierarquicamente predeterminam sujeitos e, consequentemente, explicam um racismo velado explicitados nas respostas. Daqui por diante identificaremos as turmas por $\mathrm{T}$, seguida de A, B, C etc., e alunos/as por A, seguida de um número, identificador do indivíduo. $\mathrm{Na}$ primeira aplicação do questionário, o pertencimento à nacionalidade é mais expressivo na TA do que nas TB e TC. Na TB, é nítido o posicionamento excludente do negro. Na TC, há um claro conflito entre "escravos" e "escravidão", termos utilizados por sete acadêmicos/as, e "força, esperança, persistência, superação, revolução e guerreiro", termos propostos por seis acadêmicos/as.

Esta aplicação traz à luz da reflexão o processo proposto, destacando alguns aspectos: as TA, TB e TC se dão conta do preconceito frente ao negro.

Esse processo de sentido histórico, se efetiva, segundo Rüsen (2015, p. 98), ao analisar este sentido, porque nele "o passado atua como elemento prévio e o futuro como elemento por vir, em conjunto, no presente. São um só acontecimento na constituição histórica do sentido”. Já, para Freire (1996, p. 26), os acadêmicos participantes são os "sujeitos da construção e da reconstrução do saber ensinado, ao lado do educador, igualmente sujeito do processo".

Na primeira aplicação, o A13 da turma TA observou que "boa parte foi produto e mão de obra, depois marginais". Após o desenvolvimento das atividades, na segunda aplicação, ele escreveu: "Os negros foram discriminados e oprimidos; o ódio diminuiu por defenderem seus direitos e dignidade humana".

É no resultado da segunda aplicação que constatamos tais pormenores. Na TA, oito acadêmicos/as; na TB, treze acadêmicos/as, e na TC, quatorze acadêmicos/as. Observe-se a inserção representativa do significado:

- na TA: cidadão, humano, iguais, cultura, povo e ícone;

- na TB: luta, guerreiro, superação, fundamental, cultura história do Brasil, orgulho e igual;

- na TC: força, forte, luta, resistência, perseverança, persistência, superação, mudança, liberdade, sobreviventes. 
Tais observações confirmam o que Ruiz (apud ROIZ, 2018, p. 231) afirma: “[...] o problema não estava tanto em recuperar as "heranças do passado", mas em se (re)pensar o que se deveria fazer no "presente", observação que bate com a de Rüsen (2015, p. 99), segundo o qual o presente é, aqui, "fonte originária da relação interna entre experiência do passado e interpretação do futuro na compreensão do presente". Na mesma linha, Freire (1987, p. 98-99) ressalta o processo de apropriação significativa da tomada de consciência, considerando a "postura ativa na investigação". Rüsen e Freire sobre o presente, estabelecem a coesão entre passado e futuro, numa relação dialética a ser investigada.

No início do processo, para um acadêmico da Turma B o termo "negro" sugeria "pobreza, inferioridade e bandidagem”. Esta percepção nos convencia da necessidade de refletir sobre a orientação do presente e a formação da identidade histórica, não apenas no sentido de aprender um conteúdo, mas de entender o quanto, sem nos dar conta, carregamos de subjetividade e intersubjetividade (RÜSEN, 2012, p. 91-93).

Em concordância com a reflexão, Roiz declara que, o século XX continua "ainda enraizado nas atitudes coloniais portuguesas, cujo caráter 'cordial"' ainda persiste na sociedade brasileira. Aplicamos esta reflexão à análise do presente, não para "empreender "discursos ideológicos", que, inevitavelmente amarrados ao passado, excluiriam "as massas anônimas" dos processos políticos ao se debaterem as propostas políticas e sociais para o país (ROIZ apud ROIZ; GOMES; SANTANA (Org.). 2018, p. 241). Procuramos entender o termo 'Excluir', aplicado às "massas anônimas". Ficou claro que o termo deve ser interpretado como "plenamente subordinadas" em seus posicionamentos diante dos sujeitos em questão; que 'excluir' deve ser interpretado como atitude, em relação aos negros, que, por muito tempo, foram omitidos ou simplesmente esquecidos/ignorados em relação ao legado do branco, constituído por: conquista sobre uma nação; absurdos gloriosos; celebração de uma constituição federal de nobres e respectivos privilegiados. A ação velada ainda eclode numa roupagem cordial de bons modos, porém, na calada das entrelinhas, as ocorrências se mantêm nas aparências de um senhor desleal.

Aspecto de relevância, no pensamento do aluno C2, da turma TC, que declarou na primeira aplicação do questionário: "Seriam escravos, maltratados e vendidos uns aos outros". Após a finalização do processo, reaplicado o questionário, C2 respondeu: "Ainda que a situação e condições de vida dos negros tenha melhorado, não se equipara à do branco e a seus indices sociais favoráveis. Para os negros, ainda é visto rendimento salarial inferior, taxa de analfabetismo, baixa ocupação em cargos importantes, discriminação racial, mesmo com o auxílio de ONG's, associações e campanbas com o objetivo de combater o preconceito. A escravidão marcou a história desse povo que enfrenta até hoje as consequências: desigualdade social, criminalização, exploração e racismo". 
O que observamos na reação dos alunos reflete o que havíamos encontrado nos autores de apoio para o estudo, como Rüsen, Mbembe e Freire.

Rüsen (2015, p. 82) diz que a "estreita conexão existente entre pensamento histórico e ação política" contribui para a compreensão da inexistência da neutralidade. Outro autor, Mbembe (2017, p. 58-59) se pergunta: “Quem sou eu?” "Serei eu, em boa verdade, quem dizem que eu sou?” "Será verdade que não sou nada a não ser isto - a minha aparência, aquilo que se diz e que se quer de mim?” Qual é o meu verdadeiro estado civil e histórico?” Já Freire (2012, p. 29) diz que o “saber tem historicidade", que ele considera que nunca "é, mas está sempre sendo".

\subsection{Diálogo intertextual: literatura - (des)colonizando com freire e rüsen}

Cabe ressaltar que os aportes teóricos que citamos no decorrer do artigo compõem as discussões paralelas de cada etapa, como, por exemplo, o de Rüsen (2015, p. 192), coerente com a objetividade de nossa proposta, que não é transformar a narrativa literária em critério de avaliação da narrativa histórica, mas analisar a representatividade da participação dos sujeitos nesse recorte literário que compõe a presente etapa de nossa pesquisa.

Em colaboração, Mbembe (2017, p. 208) ressalta que o texto literário demonstra, "no caso dos Negros, as linguagens da recordação", e esclarece a dependência "da crítica que se faz do tempo”. Nessa relação contingente, ambígua e contraditória do tempo no texto literário em suas diversas manifestações, estimulamos a reflexão dos/as acadêmicos/as, numa incansável perspectiva de (des)fazer a trela escravagista que amordaça a integralidade do negro, refletindo sobre os processos que compõem as linguagens culturais afetadas por influências históricas, políticas, educacionais e econômicas desde que o homem descobrin o poder do registro, aspecto apresentado e comentado em aula para apimentar as discussões.

Os aportes teóricos Freire e Rüsen são de suma importância nesse processo, quando, em aula, apresentamos, para analisar e comentar, o posicionamento de Freire (1987, p. 30-31) sobre a grande tarefa humanística e histórica dos oprimidos, que é "libertar-se a si e aos opressores". Mesmo que utopicamente, é nossa ampla meta de ação educativa diante dos/as acadêmicos/as, por acreditarmos que possam tornar-se "senhores de si nas atitudes que assumem com relação aos poderes dominantes". Acreditamos poderem habilitar-se para serem eles mesmos a darem forma a suas vidas.

De sua parte Rüsen (2010a, p. 32) trabalha com o "saber histórico como força de vida e sua influência estética", que afeta não somente o racional, mas também o emocional, determinante em relações sociais. Outra importante contribuição de Rüsen (2010b, p. 134) diz respeito ao passado, cuja função é levar a refletir sobre o presente. Trata-se, especificamente, da "representação de um processo temporal". Rüsen é ainda mais enfático (2015, p. 104) quando 
utiliza uma interpretação diferente, ao considerar a narrativa histórica a representação de um processo temporal que nos provoca a agonizar - nesse agir e sofrer - no cenário do oprimido, do sujeito posto à margem de uma sociedade, daquele cujo fruto só poderia ser continuamente excluído, e no distorcido sentido maléfico do preconceito de um povo que veste a bandeira do embranquecimento cruel e desmedido na ironia de uma suposta superioridade.

Neste âmbito, "desconstrução" de conceitos, partimos para a verificação dessa consciência através do conteúdo narrativo de alguns livros brasileiros no recorte histórico literário do século XVIII ao XXI. Partimos da crise do presente para correlacioná-la ao passado. Para tanto, optamos pela apresentação de algumas personagens fictícias para, pelo contexto no qual estão inseridas, observar a representação e a participação do sujeito negro. Iniciamos com as primeiras décadas do presente século XXI; estrategicamente, a partir da leitura bibliográfica com a reflexão sócio-histórica dos acadêmicos, a começar pela obra CIDADE DE DEUS: a história de Ailton Batata, o sobrevivente -, por sua relação muito atual com o mundo do tráfico de drogas em que está imersa a personagem. Cabe alertar que não se trata da versão cinematográfica, mas da contradição que se encontra televisivamente exposta.

Acadêmicos da turma TA, ao debater em sala de aula a obra Cidade de Deus, selecionaram trechos que consideraram importantes: A história de Ailton Batata (p. 62, parágrafo 1), admitindo como significante o seguinte trecho: "Na infância, Ailton teve que trabalhar vendendo doces para seu pai; alguns policiais pegavam os doces sem pagar, provocando atrito entre Ailton e seu pai, o que resulta na sua saída de casa aos 13 anos, desencadeando um crescimento desestruturado como pessoa." Nesse contexto, o preconceito fez aflorar uma característica da situação familiar.

Já a turma TB, sobre a mesma obra, citou, em consenso, da p. 64, o parágrafo 2: “Ailton relata o motivo de desistir do trabalho, onde a falta de emprego e visão de que o tráfico oferecia dinheiro fácil." Citou também, da p. 121, o parágrafo 2: "Ailton deixa claro que o motivo para continuar no mundo do crime foi o dinheiro, pontuando a questão socioeconômica." Observou mais: "A autora relata que não se pode conceber o estudo de nenbum ser humano, sem se considerar que o mundo do sujeito é sempre biopsicossocial' (p. 285, parágrafo 3).

Neste ínterim, acadêmicos/as foram questionados/as, a partir do ponto de vista freireano (2016, p. 19) quanto à função da educação, que é a de libertar o homem em lugar de submetê-lo, de domesticá-lo, de adaptá-lo [...]". Neste sentido, aplicamos o trecho da interpretação histórica rüseniana (2010b, p. 131) que "lida sempre com a singularidade das mudanças temporais. A interpretação, por esse parâmetro, foi a de "um processo de individuação" em "contraponto entre teoria e empiria”. Ainda insistindo sobre o autor (2014, p. 101), [...], esse processo de individuação 
teria sido "construído" como tal pelas ações da consciência histórica. Esse "construir", esse posicionar-se consciente em relação à experiência do passado perfaz o modo reflexivo.

No caso da turma TC, os acadêmicos dissertaram coletivamente sobre a história de Ailton Batata, para eles desde cedo constituída na base de muita luta: expulso de casa sem nem ao menos ter certeza sobre o motivo do que acontecia. Sem dinheiro nem chances de futuro, pensou no tráfico como oportunidade de ganhar a vida. Influenciado pelo meio em que vivia, tentou manter a liberdade sem se submeter a acordos sociais. Com pouca instrução, caiu no desalento e entrou na correria criminosa, embora sua intenção inicial fosse arrumar um emprego honesto. Vivendo uma busca incessante por um sentido, Ailton consegue alcançá-lo quando é preso, o que lhe oferece a oportunidade de contar a própria história e os motivos que o levaram a cometer os crimes que se transformaram em objeto de estudo. Notam-se divergências, porém, entre o livroentrevista e a produção cinematográfica, demonstrando desencontros não-ficcionais que requerem um processo investigativo sobre as narrativas a respeito da crise exposta pelo problema presente.

A turma TA, em debate com o restante da sala em relação a Um defeito de cor, elegeu os seguintes trechos:

-- Sinhô José Carlos é o dono da casa-grande e mantinha os escravos, ou melhor, existiam escravos da senzala e escravos que serviam a casa-grande. Esméria é uma escrava que servia a casa-grande e tinha uma visão diferente dos negros da senzala. Nega Florinda é uma ex-escrava, de certa idade e carismática, que tinha muita bistória para contar... Visão do povo negro (escravos) (p. 80, parágrafo 1).

Esta turma pontuou aspectos relacionados ao cotidiano dos escravos, consequentemente, às circunstâncias a que eram submetidos, reconhecendo nisso "um ato de conhecimento, uma aproximação crítica da realidade" (FREIRE, 2016, p. 29), que também responde a Rüsen (2010b, p. 134), que indaga o que pode ser "obtido das experiências do passado, como história". Concordam com ele os/as alunos/as da turma, reconhecendo que 'história' de fato não é originalmente um problema das regras da pesquisa, mas das perspectivas acerca do passado humano, na representação daquele a quem é dada a voz da historicidade enquanto processo temporal.

A turma TB opinou sobre a escrava Esméria, por lembrar "A escrava Isaura”, que, por atuar na casa-grande, tinha uma postura preconceituosa em relação a outros grupos de mesma raça, razão por que descumpria as regras quando à noite saía com os escravos da senzala sem que ninguém a percebesse. Já a nega Florinda, uma escrava de muitos anos, livre, que visitava várias famílias em troca de comida e tinha muito contato com a sinhá, gostava da nega Florinda, mas tinha inveja de seu carisma. 
No caso da turma TC, foi questionado o título da obra. Uma separação de raças, entre senhores brancos, à época donos da senzala, quando, sob suas ordens, ou "como sua propriedade", situavam-se os negros que os serviam e eram por eles vistos como raça inferior. A respeito da Nega Florinda, no trecho - Amiga Florinda era das pessoas mais antigas da ilha; morava lá desde que tinha chegado da Africa. Já havia tanto tempo que ninguém vivo se lembrava dela como escrava observaram que ela, que já havia sido escrava e no momento, devido à velhice, não servia mais aos brancos, somente contava histórias antigas de negros para os brancos em troca de dinheiro ou prendas. A aparência física da negra Florinda é interpretada como a representação de uma pessoa que sofrera muito, caracterizada no livro como espirito dos antepassados. Era baixa, andava curvada, usava uma bata inteiriça e colorida, pano da costa jogado do lado direito, uma bolsa de tecido, vários colares coloridos, corda amarrada na cintura e roupas bem características da cultura negra.

Em discussão coletiva, a turma TA destacou dois pontos que julgava relevantes sobre Clara dos Anjos: - a visão enaltecedora sobre a mulher negra de classe baixa (p. 14, pará-grafo 1); - a visão preconceituosa e limitada da sociedade perante um relacionamento inter-racial entre duas pessoas (p. 154, parágrafo 1).

A turma TB, sobre a mesma obra, destacou: - a visão sobre uma realidade sofrida por mulheres, principalmente negras, sobre abandono quando engravidadas, mostrando o pré-conceito tanto por cor, quanto por classe social (p. 173, parágrafo 3). Na opinião da turma, Afonso Henrique de Lima Barreto retrata, de forma romantizada, mas ao mesmo tempo trágica, a vida do ponto de vista do humilhado, a violência dos brancos contra os negros, dando voz às periferias e favelas de grandes cidades. Os acadêmicos demonstraram, valendo-se de Freire (2016, p. 59), que "o respeito à autonomia e à dignidade de cada um é um imperativo ético e não um favor que podemos ou não conceder uns aos outros". Princípios de todas as questões interpretativas que Rüsen direciona nesta discussão, visto que a função explicativa de uma pesquisa histórica é "principalmente a de inserir os fatos do passado no contexto temporal em que eles encontram sua explicação histórica (narrativa)" (2010b, p. 152 153).

No caso da turma TC, os acadêmicos anotaram que, durante análise do livro de Lima Barreto, tiveram a percepção do personagem principal perante o autor. Perceberam a descrição da parte pobre de uma cidade, deixada de lado pelos governantes, apesar de arcarem com seus devidos papéis sociais, como o pagamento de impostos. Na percepção dos/as acadêmicos/as, o autor se refere às pessoas desse local como a uma minoria de uma parte social, com grande dificuldade de acesso e locomoção, principalmente nos dias de chuva. O pouco caso governamental se evidencia ainda mais, segundo os acadêmicos, na representação de um 
momento de luto. Os velórios e enterros representavam o símbolo do descaso e dos maus cuidados de uma parcela social, tratada como minoria pelo governo... Trazendo tal ideia para a sociedade real, verifica-se a persistência de um sistema apático no qual vivemos e no qual acadêmicos/as identificam o problema, analisam e contabilizam a solução, constatando, porém, que a execução da melhoria quase nunca é realizada. A quem atribuir a culpa pelo problema? E a solução, a quem compete?

A turma TA trabalhou determinados trechos da obra Pai contra mãe. Comentou o seguinte tópico: O Candido Neves se vê em um impasse em que ele deve interessar à mulata amada que estava grávida para salvar o filho dele. O autor mostra que, para a satisfação de um dos lados, o outro precisa sofrer. E no contexto do conto, o próprio narrador fala, num momento posterior à abolição da escravatura no Brasil (p. 28, parágrafo 1).

Os/as acadêmicos/as da turma TB, sobre a mesma obra, anotaram: Candido Neves, um homem branco que cedeu à pobreza, já que não tinha a vontade de aprender a crescer em um trabalho aceitando algo mais fácil que era capturar escravos fugidos. Cândido no final do conto permite literalmente a morte de outro: "Nem todas as crianças vingam", uma justificativa deplorável para gestos desumanos (p. 16, parágrafo 1).

A turma TC escreveu: O personagem principal é um caçador de escravos fugidos; entrou para esse ramo, pois, demandava algumas habilidades que ele tinha (como força, agilidade, percepsão, boa memória), demandava pouco tempo de serviço, e podia obter grandes lucros com essa atividade, apesar de ela ser escassa. Casouse com uma moça, Clara, uma costureira que morava com tia Mônica, e foram morar juntos de aluguel, e a moça engravidou. No decorrer da gravider, Candido sentia dificuldades na atividade em que trabalhava, pois não havia mais escravos para capturar, sem contar com a concorrência de caçadores. Com isso, não conseguia pagar o aluguel e foram despejados após 5 dias de aviso do aluguel atrasado. E, por fim, foi morar de favor com tia Mônica. Poucos dias depois, a criança nasceu, e, na falta de emprego como caçador e outros tipos de atividades, tia Mônica sugeriu que dessem a criança para adoção. Com muito custo, o caçador acatou a sugestão. Ao levar a criança para adoção, em um beco encontrou uma mulata cuja captura estava valendo muito dinheiro. Após capturá-la para a Alfândega, sabendo que estava grávida, manteve a captura para receber sua recompensa. Com a recompensa em mãos, pegou sua criança e a levou para casa, sendo perdoado pela tia Mônica.

Em relação à obra $O$ Cortiço, entre os acadêmicos da turma TA foi surgindo um debate, comentando particularmente alguns parágrafos, como: da página 90, parágrafo 1; da página 91, o parágrafo 3; da página 92, o parágrafo 2. Esses parágrafos, segundo os/as acadêmicos/as, retratam a diferença entre a visão de Jerônimo sobre a Rita Baiana como algo encantador. Já o português tinha uma visão dela somente como mulata. Em manifestações verbais, alguns alunos demonstraram o quanto a obra demonstra, pontualmente, nos trechos que tiveram a oportunidade 
de enfatizar e por eles optar, como, por exemplo, quando uma aluna disse que "saberei falar sobre o assunto, porque sou negra".

A conexão teórica ocorre desde a escolha dos trechos até a escolha das expressões de protesto encontradas durante a mencionada atividade. Nossa discussão, partindo da ação e reflexão dos/as acadêmicos/as, requeria que nossos aportes teóricos fizessem parte das intervenções. Para tanto, optou-se por Rüsen (2010b, p. 130), por sua contribuição a respeito da crítica das fontes do contexto narrativo, o que estimularia a capacidade explicativa e, portanto, a compreender a importância da visão crítica que conecta a Freire. A este processo, por sua vez, Freire (2002, p. 69) chamará de transitividade crítica, que consiste na "profundidade da interpretação dos problemas". Estes dois autores foram assumidos pela importância de sua colaboração no processo de formação crítica de nossos/as acadêmicos/as.

A turma TB afirma, em consenso, sobre a mesma obra, que "O exemplo de racismo fica claro quando o Miranda se refere a $O$ Cortiço de forma desumanizada, como se animais vivessem no terreno, dando ideias do negro como escravo, pobre, não racional (p. 29, parágrafo 4).

A turma TC reconheceu uma relação entre ficção realidade, por pontuar o aspecto da mulher submissa, numa sociedade adúltera e ambiciosa, na degradação dos sujeitos-negros, como vermes, sem nenhuma importância.

Tanto quanto o conteúdo programático - sobre a conscientização na perspectiva freireana e na formação da consciência histórica rüseniana, com preocupação com a cientificidade investigativa e com as atividades expostas num ato de leitura repleto de história e cultura, registrado em textos literários -, conseguiu-se provocar um indagar a respeito do negro de hoje, reportando-se ao passado para compreendê-lo. Ao fazê-lo, muitos, possivelmente, poderão contribuir para que este futuro seja historicamente visível.

Assim, pelo que fora exposto e pelo pouco que se pôde conferir, a constatação foi de uma pequenez desvalorizada e/ou aniquilada pela história da escravidão. Estes aspectos de algum modo registrados na tradição e na cultura, foram finalmente vistas pelo crivo desafiador de ver, de se ver e de nos ver nesse decurso, tão nosso enquanto responsabilidade de luta e resistência de gente da nossa gente, de povo do nosso povo, quanto de nossa raiz brasileira, metamorfoseada em miscigenação.

\section{Considerações finais}

O grande desafio foi desconstruir os discursos apresentados pelos/as acadêmicos/as dos referidos cursos superiores, especificamente os das turmas TA, TB e TC, sobre o significado da palavra 'negro', e sua participação histórica. 
O processo mostrou que eles/elas necessitaram reconhecer que o negro foi marcado social e historicamente pelo estereótipo escravagista, que o transformou em mera mão de obra. Estas verificações estimularam reflexões sócio-históricas; porém, não há receitas prontas e, muito menos, a demagogia da exigência de que todos/as façam e/ou refaçam a trajetória exposta. O que há de novo no processo é a busca por uma sociedade livre, numa união planetária de ideias e sonhos e por um grito de 'basta' à segregação.

O resultado desta pesquisa, que nos pareceu positivo, foi o de ter enfrentado os desafios do presente e do futuro em relação a todos/as os/as que estão à margem, principalmente "gente da nossa gente", de povo do nosso povo, de nossa constituída raiz brasileira em metamorfoseada miscigenação.

Conclui-se que o estímulo à formação da consciência histórica, tanto pela desconstrução de ideias maniqueístas e sobre a linearidade histórica, quanto sobre discursos racistas e egocentrados, deve ocorrer necessariamente no âmbito da educação, e, mais particularmente - pela pressuposta maior capacidade de discernimento -, no âmbito universitário.

\section{Referência}

ASSIS, Machado de. Pai contra mãe. Porto Alegre: Artes e Ofícios Editora Ltda, 2007.

AZEVEDO, Aluísio. O cortiço. São Paulo: Objetivo, Ano: s/d.

BARRETO, Lima. Clara dos Anjos. Belo Horizonte: Autêntica, 2017.

BHABHA, Homi K. O local da cultura. Belo Horizonte: Ed. UFMG, 1998.

BRASIL. Lei $n^{0} .10 .639$ de 9 de janeiro de 2003. Altera a Lei no 9.394, de 20 de dezembro de 1996, que estabelece as diretrizes e bases da educação nacional. Brasília, 2003. Disponível em: http://www.planalto.gov.br/ccivil_03/leis/2003/L10.639.htm. Acesso em: 30 ago. 2018.

FREIRE, Paulo. À sombra desta mangueira. Rio de Janeiro: Civilização Brasileira, 2012.

FREIRE, Paulo. Conscientização. São Paulo: Cortez, 2016.

FREIRE, Paulo. Educação como prática da liberdade. Rio de Janeiro: Paz e Terra: 2002.

FREIRE, Paulo. Educação e mudança. Rio Janeiro: Paz e Terra, 1981.

FREIRE, Paulo. Pedagogia da autonomia. São Paulo: Paz e terra, 1996.

FREIRE, Paulo. Pedagogia da indignação. São Paulo: Editora UNESP, 2000.

FREIRE, Paulo. Pedagogia do oprimido. Rio de Janeiro: Paz e Terra, 1987.

FREIRE, Paulo. Política e educação: ensaios. São Paulo: Cortez, 2001. 
GONÇALVES, Ana Maria. Um defeito de cor. Rio de Janeiro: Record, 2017.

HALL, Stuart. A identidade cultural na pós-modernidade. Rio de Janeiro: DP\&A, 2006.

MBEMBE, Achille. Crítica da razão negra. Tradução: Marta Lança. Portugal: Antígona, 2017.

ROIZ, Diogo da Silva. A batalha pelo uso da "temporalidade": projetos de escrita da história para pensar o Brasil entre os "homens de letras" de São Paulo no início da década de 1930. In: ROIZ, Diogo da Silva; GOMES, Geovane Ferreira; SANTANA, Israel José (Org.). Direitos Humanos e o Pensamento Social Brasileiro. 1. ed. Serra: Editora Milfontes, 2018. 280p.

ROIZ, Diogo da Silva. (Org.). A prática da história intelectual e dos intelectuais: ideias, movimentos e ações.Jundiaí: Paco Editorial, 2017.

RÜSEN, Jörn. A História entre a Modernidade e a Pós-modernidade. História: questões e debates, Curitiba, v. 14, n. 26/27, p. 80-101, jan./dez. 1997.

RÜSEN, Jörn. Aprendizagem histórica: fundamentos e paradigmas. Tradução: Caio da Costa Pereira, Daniel Martineschen, Peter Horst Rautmann, Sibele Paulino. Curitiba: W. A. Editores, 2012.

RÜSEN, Jörn. Cultura far sentido: orientações entre o ontem e o amanhã. Tradução: Nélio Schneider. Petrópolis: Vozes, 2014.

RÜSEN, Jörn. História viva - Teoria da história III: forma e funções do conhecimento histórico. Trad. Estevão de Rezende Martins. Brasília: UnB, 1. Reimp, 2010a.

RÜSEN, Jörn. Reconstrução do passado - Teoria da história II: os princípios da pesquisa histórica. Tradução: Asta-Rose Alcaide. Revisão Técnica: Estevão C. de Rezende Martins. Brasilia: Editora Universidade de Brasília, 2010b.

RÜSEN, Jörn. Teoria da história: uma teoria da história como ciência. Tradução: Estevão C. de Rezende Martins. Curitiba: Editora UFPR, 2015. 